\title{
Weather Predicates, Unarticulation and Utterances
}

\section{Richard Vallée}

Université de Moncton

Campus de Shippagan

Bibliothèque, Sciences et Tech

218, boulevard J.-D.-Gauthier

Shippagan, NB

Canada E8S 1P6

rvallee@umoncton.ca

\section{Article info}

CDD: 401

Received: 15.04.2018; Revised: 09.07.2018; Accepted: 10.07.2018

DOI: http://dx.doi.org/10.1590/0100-6045.2018.V41N2.RV

\section{Keywords: \\ Unarticulation \\ pluri-propositionalism \\ cognitive significance \\ impersonal pronouns \\ events \\ impersonal predicates}

\begin{abstract}
Perry contends that an utterance of (1) 'It is raining' must be assigned a location before being truth assessed. The location is famously argued to be an unarticulated constituent of the proposition an utterance of (1) expresses. My paper examines this view from a pluri-propositionalist perspective. The sentence (1) contains an impersonal pronoun, 'it' and the impersonal verb 'to rain. I suggest that the utterance of (1) semantically determines 'to rain', which is an event, and that that event is instantiated at a time indicated by the tense at a location It is assumed that all event are located in space and time.
\end{abstract}

\section{Weather in Semantics}

Perry, in 'Thought Without Representation' (Perry, 1986), put forward the notion of 'unarticulated constituent,' 
which, since then, has prompted an important literature. ${ }^{1}$ Let me remind you the famous example. ${ }^{2}$ One Sunday morning, in Palo Alto, Perry's son looked outside the window, and made an utterance ${ }^{3}$ of

(1) It is raining.

The utterance was true, and tennis was cancelled. Perry contends that 'In order to assign a truth value to my son's statement, as I just did, I needed a place' (Perry, 1986; Perry, 2000: 172). (1) is a complete, grammatical sentence, and it contains no lexical item designating a place. The location needed to truth assess the utterance must then be an unarticulated constituent of the truth conditions of the statement, since it is not determined by a lexical item in (1). ${ }^{4}$ Where does it come from? Perry has a strong intuition a view on (1) should account for. To answer, Perry alludes to a mild piece of metaphysics: 'it does not just rain or not; it rains in some places, while not raining in others' (172). Following that view, it does not really matter whether the location is small (Palo Alto) or large (Northern California), or if it has well determined limits. The 'rain' sentence is peculiar because it contains the truth conditionally inert expression 'it', qualified as syntactic filler in 'Thought Without Representation' (Perry, 1986: 172).

\footnotetext{
1 See Récanati, 2002, 2007; Marti, 2006; Cappelen and Lepore, 2005, 2007; Corazza; 2007; Neale, 2007; Vicente and Groefsema, 2013.

${ }^{2}$ See Korta and Perry, 2011, for a more complex description of the example.

3 I use 'utterance' rather than 'statement'.

${ }^{4}$ See also Korta, 2012 on that issue.
} 
In his paper, Perry states a basic, general principle concerning language, the principle of homomorphic representation:

'Each constituent of the proposition expressed by a statement is designated by a component of that statement' (Perry, 1986: 171).

No lexical item in (1) designates a place, and no location is a constituent of the proposition, or the truth conditions, expressed by the statement or an utterance of (1). The utterance of (1) is a counterexample to this basic principle, and it's being so underlines its importance. An account of the utterance of (1) should explain why a location is relevant for truth valuation, and where it comes from. The converse of the principle of homomorphic representation,

'Each component of a statement designates a constituent of the proposition expressed by that statement'

is a general principle part of conventional semantic wisdom. The utterance of (1) is also a counterexample to the converse of the principle of homorphic representation: the lexical element 'it' is a linguistic expression designating nothing and making no contribution to the proposition or truth conditions of the statement. An account of the utterance of (1) should make clear the role of this linguistic expression in the utterance of (1). My paper takes into consideration the utterance of (1)'s failing both the principle of homomorphic representation - questioned by the missing location - and its converse - questioned by the missing contribution of the lexical element 'it' to the truth conditions of an utterance of (1). The subsequent discussions on unarticulation, frequently widening the debate initiated by Perry, sometimes lose sights of the principles underlying it and fall short of giving an analysis 
of the failing of both principles. I want to clarify some issues, and examine the lexical element 'it' as well as the 'rain' predicate. The focus will be on the latter.

\section{The Project}

The initial 'rain problem' is simple and, prima facie, it does not depend on any specific semantic perspective. On the other hand, the two principles it questions are stated in a specifically mono-propositionalist framework, where each statement or utterance expresses one single proposition. What I aim to do here is to revisit the initial unarticulation problem under the light of Korta's and Perry's new pluripropositionalist framework (Perry, 2012). Pluripropositionalism puts utterances at the center of the stage, and it introduces many different truth conditions or contents for a single utterance by considering various factors. Pluri-propositionalism allows for a new look on those two principles. Any reexamination of the utterance of (1) should preserve the idea that there is no linguistic representation of a place. It should also cohere with the intuition underlying the example that neither is there a mental representation of a place. My proposal dispense with representations, linguistic or mental, of a location. Or so I pretend. I suggest that the utterance of (1) semantically fixes the sentence's tense and to rain. I also contend that to rain is an event, instanciated at a time given by tense, in a location. Events are all located in space and time. However, I will not argue for that metaphysical assumption in the present paper. The location of the event can be poorly defined - it needs not have clear delimitations. It does not matter as far as my view is concerned. In my perspective, 'to rain' does not determine a relation and, in contrast with Perry's 1986 view, it does not determine a relation between a location and a moment of time. 'Is raining' contains the expression 'is' and the inflexion 'ing,' fixing time, and the

Manuscrito - Rev. Int. Fil. Campinas, v. 41, n. 2, pp. 1-28, abr.jun. 2018. 
impersonal verb 'to rain,' a verb lacking an object. Following philosophical tradition, I will not talk about verbs, but about predicates, and more specifically about impersonal predicates. 'To rain' is an impersonal predicate, a predicate applying to no object ${ }^{5}$; and I contend that to understand an utterance containing an impersonal, weather predicate requires quantification over events (see also Récanati, 2007). Such quantification suggests a view on 'rain' sentence utterances that fits, and accounts for, Perry's strong intuitions about a truth conditionally relevant location. The sentence (1) contains the impersonal pronoun 'it'. Such expression is not a demonstrative in need of a gesture or a referring intention, neither is it a coreferring expression nor a bound variable. The sentence (1), or an utterance of (1) is not about an object 'it' designates. ${ }^{6}$ This impersonal pronoun is semantically inert, having a syntactic role only (Perry, 1986), and making no contribution to truth conditions of sentences or utterances. However, the impersonal 'it' is semantically important. I contend that such impersonal pronoun opens room for relevant supplemented material in contents determined by an utterance of a meteorological sentence. I will exploit the resources provided by the focus on utterances and the many contents they can carry. If utterances express thoughts, then, going back to the utterance of (1), the speaker has a thought about a location, Palo Alto for instance, with no linguistically fixed representation of that place. That is right and, I think, very important. Neither does the speaker have a mental representation of that

5 In that respect, it differs from 'to think', which is not an impersonal predicate.

6 In history, 'it' or a similar impersonal pronoun, has been wrongly assumed in some communities to be a referential expression designating a god or Nature. That was not a theoretical view, and it is not relevant to the present discussion.

Manuscrito - Rev. Int. Fil. Campinas, v. 41, n. 2, pp. 1-28, abr.jun. 2018. 
location conveyed by the utterance. However, that does not imply that the speaker has no propositional thought content. Utterances of sentence are strongly tied to beliefs. Perry's son has a belief when making his utterance, and 'Perry's son believes that it is raining' is a perfectly fine belief attribution. But what does Perry's son believe? What is his belief content? Perry also believes that it is raining. What does he believe exactly? The underlying philosophical points raised by Perry invite to a reexamination of basic principles concerning both truth conditions of utterance of sentences and thoughts. ${ }^{7}$

\section{Focussing on a Location}

Let us set aside the lexical item 'it' for now. 'Is raining' is usually, and correctly, read as a predicate. The impersonal predicate 'to rain' does not accept referring expressions or quantified terms, ranging over objects, in subject position. Arguably, such predicate does not determine the property of an object. ${ }^{8}$ Prima facie, the introduction of a location does

\footnotetext{
7 The 'rain' argument gives rise to many different suggestions. Some focus on the sentence used and are syntactic in nature: it is proposed to modify the logical form of rain sentences and to add arguments to 'rain' (Corazza, 2007; Neale, 2007). Some focus on the world, take a metaphysical approach and argue that the natural phenomenon of rain requires a location (Perry, 1986). Recent discussions downplay the representational problem raised in 'Thought without Representation'. They also shift from issues connected to location and speakers, and embrace all components appropriate for understanding and truth assessment of utterances (Récanati, 2002).

8 Tense can be modified ('was' or 'will be'), and any similar meteorological verb can be substituted to 'to rain'.
} 
not have to do with the syntactic structure or the semantics of the sentence.

Different, complex examples emerged in the literature, among which, 'Everytime I light a cigarette, it rains'. Such sentences suggest quantification over locations, that is, it conveys something like 'everytime and wherever I light a cigarette, it rains at that place'. Such reading of what can be carried by the sentence is quite intuitive. I will come back to it. Clearly, the 'rain' example should be distinguished from incomplete sentence utterance to capture the specific issues it raises. It obviously differs from utterances of subsentential fragments, 'on the bookshelf for instance (Korta and Perry, 2011). 'Rain' sentence utterances should also be distinguished from complete sentence utterances, which are true or false given facts, like 'Mary is dancing' (Ken Taylor, 2000). In Taylor's example, a location is prima facie neither missing nor required for truth assessment. In addition, the 'dancing' example contains no impersonal pronoun or impersonal predicate. Of course, as is frequently noticed, some sentences have unarticulated constituents. Predicates like 'be tall', in 'Peter is tall', call for a specific comparison class for truth evaluation. However, the latter is not linguistically constrained by a lexical item in the sentence. It can be any comparison class. The 'rain' example is different because of it's requiring a location and, as Perry notices, such requirement has to do with the word 'rain'. More importantly, in contrast with 'Peter is tall', (1) contains an impersonal pronoun and an impersonal predicate. The sentence (1) should also be distinguished from sentences, or utterance of sentences, like 'I've had a very large breakfast' (Récanati, 2002) or 'you are not going to die' (Bach, 1994; Récanati, 2002), which contain neither impersonal predicates nor impersonal pronouns. Downplaying these differences blurs the importance of the problems raised by (1). The sentences I set aside do not contain an impersonal predicate and the 
impersonal pronoun 'it', which both play major roles in Perry's paper. That being said, let me introduce the pluripropositionalist framework.

\section{Pluri-propositionalism}

An utterance is an action individuated by a speaker, a location, a moment of time, and a sentence as type. Changing one of these parameters results in a different utterance. Utterances are usually assumed to express one single proposition, and so does Perry in his original paper. ${ }^{9}$ Focussing on only one proposition is sometimes confusing because it neglects some aspects of sentences and utterances. Pluri-propositionalism can clarify the ongoing debate on 'rain' sentences. On that view, linguistic meaning is attached to linguistic expressions as type. In that respect, the new approach follows the philosophy of language tradition. 10 Yet, pluri-propositionalism focusses on utterances rather than sentences as type, and it is designed to account for context sensitive expressions, like 'I', and utterances of sentences containing such expressions. It also introduces the idea that an utterance conveys various propositions, contents or truth conditions. Hence, the principle of homomorphic representation is abandoned in the new framework.

The sentence

(2) I am dancing.

9 I do not address all the issues raised in 'Thought Without Representation', including those conncected to concern and about.

10 Sentences as type are abstract entities.

Manuscrito - Rev. Int. Fil. Campinas, v. 41, n. 2, pp. 1-28, abr.jun. 2018. 
has linguistic meaning as type, and the meaning of ' $\mathrm{I}$ ' is utterance reflexive. It determines the speaker of $u$, where $u$ is the utterance itself. Such sentences can be used by different speakers, in different locations and at different moments of time to talk about themselves. In day-to-day life, we are in contact with utterances made by speakers, not with sentences as type. ${ }^{11}$ The linguistic meaning of an expression as type is a rule determining contents of utterances. Meaning is not a truth valuable entity (Perry, 2012). Perry submits that

If there is some aspect of meaning, by which an utterance $u$ of $S$ and an utterance u' of S' differ, so that a rational person who understood both $S$ and $S^{\prime}$ might accept $u$ but not u', then a fully adequate theory of linguistic meaning should say what it is (Perry 1988; Perry 2000: 194).

A speaker may accept as true an utterance of (2), and reject as false a different utterance of the same sentence. Such phenomenon calls for an explanation. Perry (1988) offers an important element of that explanation by proposing the following conditions on cognitive significance:

(a) The cognitive significance of an utterance $S$ in language $\mathrm{L}$ is a semantic property of the utterance;

(b) It is a property that a person who understands the meaning of $S$ in $L$ recognizes;

(c) The cognitive significance of an utterance of $\mathrm{S}$ in $\mathrm{L}$ is a proposition;

(d) A person who understands the meaning of $\mathrm{S}$ in $\mathrm{L}$, and accepts as true an utterance of $\mathrm{S}$ in $\mathrm{L}$, will

${ }^{11} \mathrm{I}$ assume that speakers are linguistically competent and speak literally. 
believe the proposition that is the cognitive significance of the utterance

(Perry, 1988: 194).

I want to emphasize that these conditions focus on the utterance's meaning and on its being accepted as true. Most importantly, they are not about truth after taking extralinguistic facts into consideration, and extralinguistic facts are not relevant to a given utterance's cognitive significance. So far as cognitive significance is determined by linguistic meaning only, let us say that it is a meaningbased notion. Of course, like any proposition, as is emphasized in (d), the cognitive significance of an utterance can be the content of a belief. The cognitive significance of utterances is a new player in the field and is an important notion so as to account for differences between utterances as well as attitudes toward utterances.

Consider now the utterance $\mathbf{u}$ of (2) with the linguistic meaning of ' $\mathrm{I}$ ' in mind. The meaning of ' $\mathrm{I}$ ' designates the speaker of the utterance, myself, and it is reflexive to the utterance. $^{12}$ From here on, I will introduce the different contents obtained when various factors are taken into account. It is very important to remember that these are contents of the same utterance, and that only factors exploited to give contents or truth conditions are different.

(3) Given facts about language only, the utterance $\mathbf{u}$ of (2) is true if and only if the speaker of $\mathbf{u}$ is dancing.

The speaker of $\mathbf{u}$ is dancing gives the cognitive significance of the utterance. ${ }^{13}$ The cognitive significance of first-person sentence utterances is utterance reflexive. As an abstract

\footnotetext{
12 See Perry, 2001, for more on indexicals.

${ }^{13}$ One can also give the speaker of $\mathbf{u}$ dances at the time of $\mathbf{u}$.
} 
entity, the reflexive content classifies what goes on in the speaker mind. Clearly, you can believe that the speaker of the utterance $\mathbf{u}$ is dancing. Two utterances of (2) differ in cognitive significance because the utterances they are reflexive to are different. Referential content of utterances stems from semantically determined content after facts about the utterances - time, location and speaker - have been factored in and taken into account. The speaker of the utterance is $\mathbf{R V}$, where $\mathbf{R V}$ is the speaker himself

(4) Given facts about the utterance, the utterance $\mathbf{u}$ of (2) is true if and only if $\mathbf{R V}$ is dancing.

$\mathbf{R V}$ is dancing ${ }^{14}$ gives the referential, not utterance reflexive, content of the utterance of (2). ${ }^{15}$ Such contents are official contents of utterances and correspond to what is said. It keeps no trace of the linguistic expression used to introduce the referent in such content. It can be the referential content of a different sentence utterance, like an utterance of 'you are dancing', by a speaker talking to me. The speaker of 'you are dancing' and I make utterances differing in cognitive significance, yet having the same referential content, say the same thing and each utterance has the same truth assessment. Both cognitive significance and official content are available as thought content of the speaker. The truth assessment of utterances takes into account semantically fixed material, context and it connects utterances to extralinguistic facts. The cognitive significance of an utterance is an upper-bound proposition or content

\footnotetext{
${ }^{14}$ I italicize contents when theses contents are mentioned in the text.

15 One can also give $\mathbf{R V}$ dances at the time of $\mathbf{u}$. The content is utterance reflexive. I set aside tense for this example. In the 1986 paper, Perry does not pay attention to tense and on how it is echoed in semantically determined contents of an utterance.
} 
of an utterance in that it is reflexive and echoes meaning only; referential content is a lower-bound content reflecting both the meaning of the utterance and facts about the utterance, and it contains no reference to the utterance. The referential content is usually considered in the truth assessment of an utterance. Many contents can fit in between cognitive significance and referential content (Perry, 2012). ${ }^{16}$ These propositions or contents are all available candidates to consider for truth assessment of utterances. ${ }^{17}$ The initial 'rain' utterance problem concerns the truth assessment of an utterance of a sentence containing the nonreferring pronoun 'it' and 'to rain'. The many truth conditions and their roles give a new angle on the contribution of 'it' and 'to rain' to contents, and on the notion of unarticulation. Such contents are introduced after considering various factors, some of which are close to linguistic meaning, and some closer to facts. A speaker's understanding of an utterance of (1) rests on these many factors.

${ }^{16}$ For an utterance of 'John wants you to read the first paper published by Keith Donnellan' more that two contents can be extracted.

17 The controversy between Cappelen-Lepore and Perry about the truth of (1) can be looked at in a different way once many contents are on the table for truth assessment. Is cognitive significance or official content under consideration? Cappelen and Lepore seem to have what Perry calls the cognitive significance of the utterance in mind, while Perry himself appears to have an enriched version of official content in mind. Cappelen and Lepore take 'it' to contribute to the proposition an utterance of (1) conveys. Perry does not. 


\section{Pluri-propositionalism and 'Rain'}

Let us go back to (1). Like any predicate, 'to rain' has linguistic meaning as type and, in contrast with adjectives, it can be tensed, as in (1). Time is linguistically given in (1) and it is echoed in the meaning determined truth conditions of the utterance, or in its cognitive significance. 'To rain' is arguably a standard one place predicate, where the expression ' 'it' is the relevant argument. 'It' does not have linguistic meaning to be grasped to understand the linguistic meaning of (1), and it finds no echo in semantically determined truth conditions or contents of the utterance. The expression 'it' does not bring in any component to the cognitive significance of the utterance of (1). However, this expression plays a major role in contributing to an affirmative grammatical sentence, as in (1), the latter being a linguistic entity fit to convey truth, or to carry truth valuable contents of utterances. The impersonal 'it' is widespread in natural languages and has the same role for different meteorological sentences: 'it is windy', 'it is snowing', and so on. That linguistic expression is an argument for the predicate in (1). Even though it introduces nothing in terms of content, it plays a semantic role in opening room for truth conditional elements in the content of utterances. A linguistically competent speaker hearing an utterance of (1) relies on his knowledge of the words used, both their syntax and their meaning. Such speaker knows that 'it' has a syntactic role only, and that 'is' and the inflexion 'ing' both determine time. The speaker also knows that 'to rain', in contrasts with 'to eat' for instance, neither determines a property of an object nor is it used to attribute a property to an object. It is an impersonal predicate. 'Peter is raining, or 'trees are raining' are grammatical, but they do not mean much literally. Their literal utterances also lack cognitive significance. It is puzzling what accepting as true a literal utterance of 'trees are raining' would be. Moreover, it is hard so see what

Manuscrito - Rev. Int. Fil. Campinas, v. 41, n. 2, pp. 1-28, abr.jun. 2018. 
would make true such sentences or utterances of such sentences. The predicate 'to rain' shares these features with many meteorological predicates. To rain is not a characteristic of an object, but it is an event. One can contend, with Récanati, that the utterance of (1) is true if and only if rain, or a 'rain' event, is occurring (Récanati, 2007: 130; Korta, in conversation). Récanati's intuitions are widely shared. It is arguable that meteorological predicates are predicates for events, or one place predicates for events: 'rain, e'. Linguistically competent speakers also know that these predicates are event predicates. However, there is no linguistic expression designating or naming the event in (1), and in any meteorological sentence. 'It' does not.

Speakers making utterances of (1) in different locations make utterances that can be true or false. A rational speaker can make a true utterance of (1), and a false different utterance $\mathbf{u}$ ' of the same sentence. A speaker hearing an utterance of (1) in Palo Alto can take the utterance to be true. One hearing a simultaneous utterance of (1) in Death Valley can take the utterance to be false. Even if using the same sentence, the speakers may nonetheless make utterances prima facie true or not. These differences should be explained. Finally, a rational speaker can make a true utterance of (1), and also a true utterance of it is not raining'. These utterances are true if they are about different location, for example London and Death Valley respectively. Due to features of events, like rain, such predicates intuitively convey a room for a location, because events are located in space and time. In that respect, weather predicates motivate the introduction of a location without articulating any specific location. However, an explicitly fixed location is missing from (1). Any proposal concerning 'to rain' should account for similar meteorological verbs. In contrast with Recanati (2007), I do not take 'to rain,' or similar verbs, to be zero-place arguments. Focussing on the metaphysics of rain, rather 
than paying attention to quantification over events and features of events, misses a more general explanation.

Consider the utterance $\mathbf{u}$ of (1) again, with knowledge of syntax and linguistic meaning only. Perry suggests a meaning-based notion of cognitive significance. Such notion can be widened by considering the category of terms, meteorological predicates, not just their meaning, and events, and then slightly altering the conditions on cognitive significance of utterances. Alternatively, being an impersonal meteorological predicate applying to events can be argued to be an aspect of the meaning of such predicates and to be cognitively significant for that reason. I will not advocate one view over the other. In any case, the linguistic categories of impersonal predicate and event predicate are prima facie cognitively significant. No specific location is explicit or articulated in the sentence (1), but a room is opened by 'it' to give the cognitive significance of this meteorological predicate utterance, or of any similar meteorological sentence utterance. In the following, ' $e$ ' is a variable for events, ' $P$ is a variable for a location and $\mathbf{u}$ is the utterance itself. The relevant sentences are about events, like rain or drizzle, events quantified over to obtain cognitively significant and acceptable as true contents: there is an $\mathrm{e}$, rain e at the time of $\mathbf{u}$ in $l$; there is an e, snow e at the time of $\mathbf{u}$ in l; there is an e, drizzle e at the time of $\mathbf{u}$ in l; there is an e, hails $e$ at the time of $\mathbf{u}$ in $l$. The component there is an $e$ binds that variable for event in the content of the rain predicate, rain e. This component is the same for all meteorological predicates, and it does not change for different utterances of the same sentence, (1) for example, or when that sentence is embedded in propositional attitude predicates. In that respect, it is utterance insensitive. 'It' opens room for there is an $e$ in contents, including the cognitive 
significance of an utterance of (1). ${ }^{18}$ Events are located in space, and introducing a variable for an event quantified over introduces as well a location. Now, it should be emphasized that the predicate, or the sentence used, does not semantically provide a specific location, and it does not contribute any specific location to the cognitive significance of the utterance. It is arguable that linguistically competent speakers master the category of impersonal predicates, including the category of weather predicate, and the category of event predicates. Perry's intuitions are grounded in both language - features of meteorological predicates, like 'to rain' - and metaphysics - events are located in space and time. These intuitions are accounted for not by the metaphysics of rain, but by meteorological predicates and category of entities, events, quantified over in language. I share Récanati's intuitions considering quantification over events. However, I take it to fill part of the role of cognitive significance of the utterance. Clearly, such intuitions do not justify the introduction of a specific location like Palo Alto.

If I am right, a linguistically competent speaker making or hearing an utterance of (1), and using linguistic knowledge only, understands that there is rain somewhere at the time of the utterance. Let me put it in a slightly different way, using quantifiers and variables, fit to exhibit some important relationship between the predicate and a location, yet easy to read in an informal way.

(5) Given facts about language only, the utterance $\mathbf{u}$ of (1) is true if and only if there is an e, there is an l, rain e at the time of $\mathbf{u}$ in 1 .

${ }^{18}$ I contend that the impersonal 'it' opens room for material in cognitive significance, not that it always opens room for the same material. Such material heavily depends on the predicate. 
The utterance is true if and only if there is a rain event at a location at the time of the utterance. These truth conditions, the cognitive significance of the utterance of (1), are reflexive. No specific location is part of these truth conditions. Moreover, the size and limits of the location, whatever they are, are not specified in these truth conditions. ${ }^{19}$ Finally, the specific location of rain can be the location of the utterance, but it can also be a different location. The utterance of (1) is silent on that point. I assume that an utterance $\mathbf{u}$ of 'it is raining' and the content there is an $e$, there is an l, rain $e$ at the time of $\boldsymbol{u}$ in $l$ are cognitively equivalent in that in accepting the utterance $\mathbf{u}$ as true one is bound to accept as true the given cognitive significance of $\mathbf{u}$ and vice-versa. Accepting as true the utterance and rejecting the given cognitive significance would be incoherent. One can also rationally accept as true an utterance $\mathbf{u}$ of (1) and reject as false a different, simultaneous utterance $\mathbf{u}$ ' of the same sentence. These utterances must be about different locations, but the specific locations these utterances are about are not explicit in the utterances, and go beyond meaning and cognitive significance. There is a clear relationship between (1) and

(6) It is raining here.

Such relationship shows in the cognitive significance of an utterance of (6)

(7) Given facts about language, the utterance $\mathbf{u}$ of (6) is true if and only if there is an e, rain e at the time of $\mathbf{u}$ at the location of $\mathbf{u}$.

The cognitive significance of an utterance of (6) makes clear that (6) is much less flexible than (1) as far as location

${ }^{19}$ I want to emphasize that they are not in Perry's paper.

Manuscrito - Rev. Int. Fil. Campinas, v. 41, n. 2, pp. 1-28, abr.jun. 2018. 
is concerned. Quantifying over events proves useful when considering negation. An utterance $\mathbf{u}$ of

(8) It is not raining

has the following truth conditions

(9) Given facts about language only, the utterance $\mathbf{u}$ of (8) is true if and only if it is false that there is an e, there is an l, rain e at the time of $\mathbf{u}$ in 1 .

The cognitive significance of (8) is that it is false that there is an event of raining in a location at the time of the utterance $\mathbf{u}$. (8) provides no information about any specific location. In a way, it can always be accepted as true. The cognitive significance of an utterance is fit for truth assessment of an utterance. However, it is general and it is not specific enough to be about a precise location. The speaker making an utterance of (8), just like the speaker making an utterance of (1), should be talking about a specific place to make a true or false utterance.

An utterance of (1) can be made in Palo Alto, yet it can be about Death Valley, or vice-versa, and then be true or false given facts. ${ }^{20}$ Whatever the specific location, it is beyond the cognitive significance of an utterance of (1), and hearers must rely on the speaker's intentions for instance to identify the specific location the utterance is about. What is said is an expression properly used to qualify what is semantically determined. What the speaker is talking about in making an utterance of (1) is not semantically determined, and I suggest to call it what the speaker meant. Remember that cognitive significance takes into account language only - and Death Valley is beyond language. The cognitive significance of an utterance of (1) does not

${ }^{20}$ The same goes for an utterance of (8).

Manuscrito - Rev. Int. Fil. Campinas, v. 41, n. 2, pp. 1-28, abr.jun. 2018. 
introduce facts and it is not specific about a location. For these reasons it is not standardly considered in truth assessment.

We can go further than cognitive significance and what facts about language make available, and focus on facts about the utterance, including the speaker intended location of the 'rain' event when making an utterance, to give various contents of the utterance of (1). We are not changing the cognitive significance of the utterance, and the latter stays the same. Speakers then exploit cognitive significance. Plausibly, the speaker intends the location of the 'rain' event to be the location of the utterance.

(10) Given facts about the utterance, the utterance $\mathbf{u}$ of (1) is true if and only if there is an e, rain e at the time of $\mathbf{u}$ at the location of $\mathbf{u}$.

More than meaning is relied on to determine this content of the utterance, and it is arguable that it is what the speaker meant. Still, these truth conditions are utterance reflexive. We do not have the name of that location, and lack less reflexive truth conditions. Under this reading, an utterance of (1) and an utterance of (6) then have the same content. However, the content of an utterance of (6) is obtained by considering meaning only. Perry assumes that his son's utterance and the rain are colocated. He also assume that himself and his son are colocated when truth assessing the utterance. There is no need to identify any specific location. Colocation is enough. The utterance of (1), plus the speaker's intention concerning the location of the utterance, gives appropriate truth conditions for truth assessment of the utterance. All the conditions to stay in bed are aligned. Perry needs no sophisticated extralinguistic knowledge to do so. In that respect, John and his son share a belief having the same content: there is rain at the time of the utterance of (1) at the location of the utterance of (1). It 
is easy to introduce facts and obtain less reflexive truth conditions. Suppose that his son's utterance is intended to be specifically about Palo Alto. Now, such an intention is strongly linguistically constrained by the predicate being an event predicate introducing a location. The precise location is not articulated and semantically determined, and an intention is needed.

(11) Given facts about the utterance, the utterance $\mathbf{u}$ of (1) is true if and only if there is an e, rain e at the time of $\mathbf{u}$ in Palo Alto.

PALO ALTO is the location itself. Now, to give the name of a location is very specific and determines a welldefined place, one clearly not provided by the utterance. It goes well beyond what is determined by meaning. Still, it can be considered for truth assessment of the utterance. Given the time of the utterance, we can add with no specific intention needed

(12) Given facts about the utterance, the utterance $\mathbf{u}$ of (1) is true if and only if thre is an e, rain e at $\mathbf{1 0}$ am at the location of the utterance $\mathbf{u}$.

where $10 \mathrm{am}$ is the moment of time. Finally, adding speaker's specific intention

(13) Given facts about the utterance, the utterance $\mathbf{u}$ of (1) is true if and only if there is an e, rain e at $\mathbf{1 0}$ am in Palo Alto.

These different contents of an utterance of (1) are obtained by going beyond what a semantically competent speaker understands and by considering relevant, nonsemantic factors, for example the speaker's linguistically constrained intention. I want to emphasize that such contents are not obtained by inference. They are just 
supplemented by taking into account extralinguistic facts, namely the linguistically constrained intentions of the speaker, to give different contents of the utterance. Clearly, nothing semantically constrains the utterance to be about the place of the utterance, and the utterance could well be about a place different from it, say Murdoch. Once again, the speaker's intention might matter.

(14) Given facts about the utterance, the utterance $\mathbf{u}$ of (1) is true if and only if there is an e, rain e at the time of $\mathbf{u}$ in Murdoch.

MURDOCH is the place itself. We have now different options, given in (5), (10), (11), (12), (13) and (14) for assessing the truth of the utterance of (1). (5), which echoes the linguistic meaning of the utterance only and gives its cognitive significance, is a serious contender. However, it is very general. (10) takes into consideration the speaker's plausible intention, and is a very serious competitor. (11), (12), (13) are not plausible candidates, because of taking extralinguistic facts into consideration and targetting a very, and uselessly specific, location and time. (14) is to be excluded, clearly not being the location Perry's son utterance is about. An utterance of (6) plausibly has a referential content containing Palo Alto itself, where Palo Alto is the location of the utterance. However, I do not want to argue that an utterance of (6) has this referential content without the relevance of speaker's intention. In addition, it is arguable that there is no specific location intended by the speaker making this utterance. Hence, I will not take a position on that last issue. 


\section{Beliefs and Quantification over Events}

What does John believe? Consider an utterance of

(15) John believes that it is raining.

We have the following options, including some taking into account John's plausible linguistically constrained intentions.

(16) Given facts about language, the utterance $\mathbf{u}$ of (15) is true if and only if John believes that there is an e, there is an $l$, rain e at the time of $\mathbf{u}$ in $l$.

(17) Given facts about the utterance, the utterance $\mathbf{u}$ of (15) is true if and only if John believes that there is an e, rain e at the time of $\mathbf{u}$ in the location of $\mathbf{u}$.

(18) Given facts about the utterance, the utterance $\mathbf{u}$ of (15) is true if and only if John believes that there is an $e$, rain e at the time of $\mathbf{u}$ in Palo Alto.

(19) Given facts about the utterance, the utterance $\mathbf{u}$ of (15) is true if and only if John believes that there is an e, rain e at $10 \mathrm{am}$ at the location of the utterance $\mathbf{u}$.

(20) Given facts about the utterance, the utterance $\mathbf{u}$ of (15) is true if and only if John believes that there is an e, rain e at $\mathbf{1 0}$ am in Palo Alto.

(21) Given facts about the utterance, the utterance $\mathbf{u}$ of (15) is true if and only if John believes that there is an e, rain e at the time of $\mathbf{u}$ in Murdoch.

(16) and (17) give the truth conditions of the most plausible belief attributions, the others being, again, far too specific. And as it is made clear in Perry's paper, $l$ is the location of 
the utterance of (1). However, that is not echoed in (15) and, in (16) as well. (21) does not give the truth conditions of a plausible belief attribution.

I mentioned a famous example at the beginning of the paper,

(22) Everytime I light a cigarette, it rains.

Now that quantification over events is introduced, we can come back to (22). I allow myself some simplification to go to my main point. An utterance of (22) has the following truth conditions:

(23) Given facts about language only, the utterance $\mathbf{u}$ of (22) is true if and only if for every e, for every moment of time $t$ and for every 1 , if the speaker of (22) lights a cigarette $e$ in 1 at time of e, then there is an e', rain of e' time of e' in l'

(22) is not specific and no intention concerning time and location are prima facie required. It is not part of the meaning of (22) that $e$ and $e$ are collocated and that $l$ is $l$ '. For (24)

(24) Everytime it rains, I light a cigarette

we have

(25) Given facts about language only, the utterance $\mathbf{u}$ of

(24) is true if and only if for every e, for every moment of time, for every 1 , if rain e at the time of e in location of e, then there is an e' the speaker of (24) lit a cigarette e' at time $e^{\prime}$ and location $\mathrm{e}^{\prime}$. 
Once again, there is no speaker intention regarding time and location. (24) does not semantically convey that $e$ and $e^{\prime}$ are colocated.

For an utterance of

(26) Everywhere I go, it rains.

we have

(27) Given facts about language only, the utterance $\mathbf{u}$ of

(26) is true if and only if for every e, for every moment of time, for every location 1 , if the speaker of (26) goes to 1 , then there is an e rain e at time e in 1 of e.

(26) does not semantically convey any specific location of rain.

Let us go back to (1). Récanati (2002: 306) suggests that the added component, a specific location, is part of what the speaker means by the utterance. I agree. However, my view is in a way less demanding. It is also more constraining - given 'rain' what the speaker mean must be about a location. A content can be obtained as cognitive significance only, and there is no need rely on the speaker's intention. Récanati (2002: 306) contends that 'To understand the speaker's utterance of 'it is raining', one must know which place is such that the speaker's utterance is true if and only if it is raining at that place'. My view is much less demanding here. From my perspective, understanding an utterance of (1) can be reduced to understanding the linguistic meaning of the sentence used and the cognitive significance of the utterance. Understanding it does not require exploiting extralinguistic facts. In Pluri-propositionalism, many truth conditions are on the stage. Do they a share a relationship? Consider the 
intuitive if controversial inference from 'it is raining' to 'it is raining somewhere' (Récanati, 2007). From a monopropositionalist perspective, it makes perfectly good sense to examine such an inference and inferences from content to content. Récanati (2007) argues that these propositions or contents are equivalent. Pluri-propositionalism offers a different view. From Perry's son utterance of 'it is raining' one easily gets semantically determined truth conditions, there is a rain event at the time of the utterance in a location. It is easy to quantify over places: there is a place where it is raining now, or it is raining somewhere now. Récanati's intuitive inference is not to be found in pluripropositionalism, and the material it makes explicit does not go beyond cognitive significance of the utterance. Adding facts about the utterance, the speaker's intentions or assumptions, and the relevance of the utterance, one can add a specific location: it rains at the time of the utterance in Palo Alto. However, what is then truth assessed goes well beyond what is semantically fixed by an utterance of (1).

\section{Conclusion}

A 'rain' sentence utterance is about a location. This is the lesson to be learned from Perry's example. However, no specific location is specified by the sentence, and to obtain a determined location, more than language is needed. Linguistically constrained intentions are required. Weather predicates raise interesting questions pluripropositionalism can answer. The celebrated unarticulated constituents, like specific locations, are not components of semantically determined content. Yet, such constituents are not totally language independent. Mono-propositionalism fails to capture that aspect of meteorological expressions. Pluri-propositionalism is more appropriate for exhibiting the complex relationship between meaning and contents. 
Pluri-propositionalism has other welcomed consequences as far as the two basic principles introduced at the beginning of the paper. Such principles are part of folksemantics, and they are at the foreground in philosophy of language. If I am right, the principle of homomorphic representation, as well as the converse of the principle of homomorphic representation, do not have full generality, and do not apply to all sentences. However, this has no impact on the utterance of some sentences and on their conveying truth conditions. The principle of homomorphic representation is questionable and, as is now widely believed thanks to comparative adjectives, it provides an oversimplified picture of language. That principle is also abandoned in pluri-propositionalism. The converse of the principle of homomorphic representation is also questionable. The role of 'it' has been underestimated in the literature, and examining it opens new perspectives on language. This issue did not receive much attention, and impersonal pronouns remain largely unexplored in philosophy of language.

\section{References}

Aliseda, ATOCHA, Rob VAN GlabBECK and DAG WESTERTHAT (eds.), Computing Natural Language. CSLI Publications : Stanford, 1998

CAPPELEN, HERMAN and ERNEST LEPORE, Insensitive Semantics. Blackwell, 2005.

CAPPELEN, Herman and ERnESt LePORE, 'The Myth of Unarticulated Constituents'. In O'Rourke, Michael and Corey Washington (eds) (2007), pp. 199-214.

CORAZZA, EROS, 'Thinking the Unthinkable : an Excursion into Z-Land'. In O'Rourke, Michael and Corey Washington (eds) (2007), pp. 427-450. 
Grice, Herbert Paul, 'Logic and Conversation'. In Studies in the $W$ ay of Words, Cambridge, Mass.: Harvard University Press, (1989), pp 22-40.

KorTA, KePA, 'Holmes, Perry, and Reference'. In Newen, Albert and Ralph van Riel (eds.) CSLI Publications (2012), pp. 33-52.

KORTA, KEPA AND JOHN PERRY, Critical Pragmatics. An Inquiry into Reference and Communication. Cambridge: Cambridge University Press, 2011.

NeAle, StePhen, 'On Location'. In O'Rourke, Michael and Corey Washington (eds) (2007), pp 251-393.

Newen, Albert and RALPH VON Riel (eds.), The Signifying Self: Introduction to the Philosophy of Jobn Perry. CSLI Publications: Stanford, 2012.

O’ROURKe, MichaEL and COREY WASHINGTON (eds), Situating Semantics. Essays on the Philosophy of John Perry. MIT Press, 2007.

PERrY, JOHN, 'Thought Without Representation'. Supplementary Proceedings of the Aritotelian Society 60, pp 263-283,1986. Repr. in Perry, J., (2000), pp. 171-188.

Perry, JOHN, 'Cognitive Significance and New Theories of Reference'. Noûs, 22, pp 1-18, 1988. Repr. in Perry (2000), pp. 189-206.

PERry, JOHN, 'Indexicals, Contexts and Unarticulated Constituents'. In Aliseda, A, R. van Glabbeck and D. Westerstahl (eds.), Computing Natural Language (eds.) (1998) pp 1-12.

PERRY, JOHN, 'Situating Semantics: A Response'. In O'Rourke, Michael and Corey Washington (eds) (2007), pp 507-575. 
Perry, JoHn, The Problem of the Essential Indexical and Other Essays. Expanded Edition, CSLI Publications: Stanford, 2000.

Perry, John, Reference and Reflexivity. Second edition, CSLI publications: Stanford, 2012.

RÉCANATI, FRANÇOIS, 'Unarticulated Constituents'. Linguistics and Philosophy 25, pp 299-345, 2002

RÉCANATI, FRANÇOIS, 'It is raining (somewhere)'. Linguistics and Philosophy 30, pp 123-146, 2007.

TAYLOR, KEN, 'Misplaced Modification'. In O’Rourke, Michael and Corey Washington (eds) (2007), pp 215-250.

Vicente, Begonia and Marjolein, Groefsema, 'Something out of nothing? Rethinking unarticulated constituents'. Journal of Pragmatics, 47, pp 108-127, 2013

$(\mathrm{cc})$ EY 